\title{
Gastroenterology in the Trent Region in 1992 and a review of changes since 1975
}

\author{
B B Scott
}

\begin{abstract}
A survey of all gastroenterologists in the Trent Region (population $4 \cdot 7$ million) showed that in 1992 the number of upper gastrointestinal endoscopies had continued to rise considerably. There were 8.6 per thousand of the population. Colonoscopies had also increased to 1.4 per thousand. There had been a large fall in barium meal examinations to 4.8 per thousand. Barium enema examinations had increased slightly to 5.3 per thousand. The number of endoscopic retrograde cholangiopancreatographies (ERCPs) and variceal sclerotherapies had also increased by $54 \%$ and $21 \%$ respectively since 1986 and were available in most of the 20 hospitals. Percutaneous endoscopic gastrostomy had been introduced at most hospitals. Emergency endoscopy was readily available at night in only half the hospitals. Fourteen hospitals offered formal open access endoscopy. Intravenous sedation was used routinely in 12 hospitals. The rate for perforation at routine upper gastrointestinal endoscopy was 1 in 4500 and for death was 1 in 20000 . There were serious deficiencies in provision of facilities or staff, or both at 14 hospitals. The total number of gastroenterologists had only increased from 25 to 26 since 1986. Thus
\end{abstract}

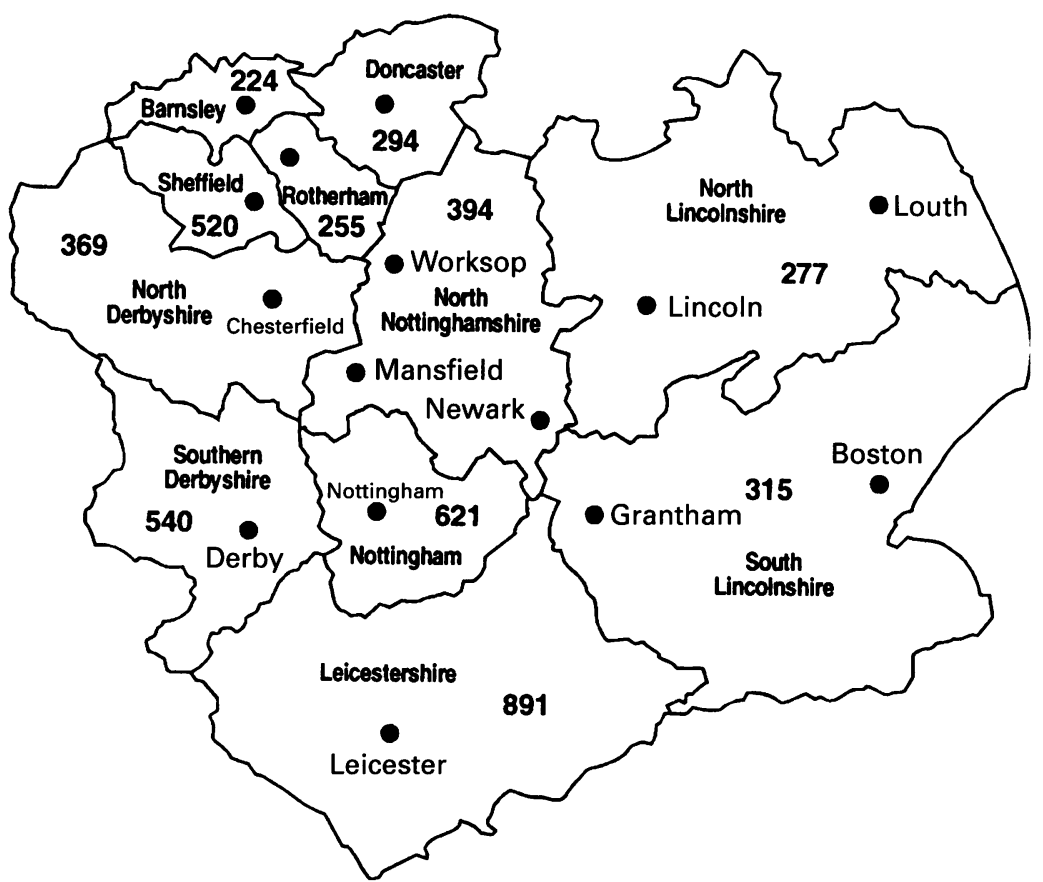

Figure 1: The Trent Region, showing the provisional rebased mid 1991 population estimates (in thousands) for each district health authority. The towns having the main hospitals are also shown. endoscopy workload continues to increase and diversify often without adequate staffing, facilities, and funding.

(Gut 1995; 36: 468-472)

Keywords: gastroenterology, endoscopy, barium examination.

Gastroenterological problems have always constituted a large part of general internal medicine. In the past quarter century, with the widespread introduction of flexible fibreoptic endoscopy, the practice of gastroenterology has changed almost beyond recognition and endoscopic procedures have formed an increasingly large part of the workload. Usually, a gastroenterologist, while also taking a full share of acute general internal medicine, provides a diagnostic and therapeutic service for the district in a similar way to a radiologist. The size of this additional and increasing commitment is not readily appreciated nor is it taken into account in strategic planning. Population based figures for the workload are essential for such planning. Trent is a large health region in central England, which is fortunate in having complete figures for endoscopic workload in various years since 1975 . Published surveys of workload and changes were made for the years 1975 and $1981^{1}$ and 1981 and $1986 .{ }^{2}$ In 1992 it was thought opportune to make a further survey.

\section{Survey}

The Trent Regional Health Authority has 11 districts (Bassetlaw and Central Notts were amalgamated as North Notts since the previous survey). Three of these districts (Nottingham, Leicestershire, and Sheffield) have a medical school. Figure 1 shows the provisional rebased mid 1991 population estimates for each district. The total population has increased from 4.414 million in 1986 to 4.700 million. A questionnaire was sent to each of the 26 consultant gastroenterologists based in the 20 general hospitals in January 1993 enquiring about workload, practices, facilities, and staffing during 1992. As for the previous surveys the response was $100 \%$. Numbers of yearly barium meal and barium enema examinations were also obtained from each district for the years 1989 to 1992 .

Upper gastrointestinal endoscopies

Table I shows the number of examinations done both by physicians and surgeons in each 
TABLE I Number of gastrointestinal endoscopies in the Trent Region in 1992

\begin{tabular}{|c|c|c|c|c|c|c|c|}
\hline \multirow[b]{2}{*}{ District } & \multirow[b]{2}{*}{ Hospital } & \multicolumn{3}{|c|}{ Upper gastrointestinal endoscopies } & \multicolumn{3}{|c|}{ Colonoscopies } \\
\hline & & Physicians & Surgeons & Total & Physicians & Surgeons & Total \\
\hline Barnsley & Barnsley & 645 & 486 & 1131 & 77 & 164 & 241 \\
\hline North Derbys & Chesterfield & 1123 & 1221 & 2344 & 169 & 349 & 518 \\
\hline \multirow[t]{2}{*}{ South Derbys } & Royal & 1200 & 100 & 1300 & 75 & 65 & 140 \\
\hline & City & 1042 & 383 & 1425 & 263 & 206 & 469 \\
\hline Doncaster & Doncaster & 1430 & 61 & 1491 & 141 & 31 & 172 \\
\hline \multirow[t]{3}{*}{ Leics } & Royal & 1000 & 1500 & 2500 & 280 & 520 & 800 \\
\hline & Glenfield & & 1480 & 1480 & 0 & 434 & 434 \\
\hline & General & 2625 & 875 & 3500 & 300 & 100 & 400 \\
\hline \multirow[t]{2}{*}{ North Lincs } & Lincoln & 789 & 304 & 1093 & 21 & 304 & 325 \\
\hline & Louth & 437 & 33 & 470 & 40 & 0 & 40 \\
\hline \multirow[t]{2}{*}{ South Lincs } & Boston & 1375 & 40 & 1415 & 172 & 110 & 282 \\
\hline & Grantham & 580 & 13 & 593 & 95 & 84 & 179 \\
\hline \multirow[t]{3}{*}{ North Notts } & Mansfield & 1724 & 282 & 2006 & 101 & 58 & 159 \\
\hline & Newark & 342 & 27 & 369 & 127 & 43 & 170 \\
\hline & Worksop & 731 & $\begin{array}{r}0 \\
400\end{array}$ & 731 & 40 & 15 & $\begin{array}{r}55 \\
200 \\
0\end{array}$ \\
\hline Nottingham & City & 2488 & $\begin{array}{r}499 \\
1007\end{array}$ & 2216 & $\begin{array}{l}215 \\
315\end{array}$ & 84 & 299 \\
\hline \multirow{3}{*}{$\begin{array}{l}\text { Rotherham } \\
\text { Sheffield }\end{array}$} & Rotherham & $\begin{array}{l}2400 \\
6000\end{array}$ & 390 & $\begin{array}{l}3493 \\
6390\end{array}$ & 45 & $\begin{array}{r}394 \\
61\end{array}$ & $\begin{array}{ll}909 \\
106\end{array}$ \\
\hline & N General & 1693 & 856 & 2549 & 180 & 226 & 406 \\
\hline & R Hallamshire & 1256 & 2689 & 3945 & 149 & 562 & 711 \\
\hline \multicolumn{2}{|c|}{$\begin{array}{l}\text { Total } \\
\text { Per } 1000 \text { population }\end{array}$} & 28197 & 12246 & $\begin{array}{r}40443 \\
8.6\end{array}$ & 2805 & 4010 & $\begin{array}{r}6815 \\
1.4\end{array}$ \\
\hline
\end{tabular}

of the 20 hospitals and Fig 2 shows the changes in the totals since 1975 . Overall there were 8.6 examinations per thousand of the population, which was an increase of $13 \%$ since 1986 . The absolute increase was $20 \%$. The increase was apparent in all except three of the hospitals. The contribution by surgeons had increased from $27 \%$ to $30 \%$. Table II shows the numbers of barium enema examinations done in each district during 1981, 1986, and 1989-1992 and Fig 2 shows the overall changes. There had been a fall, often dramatic, in all except one district, and overall there had been an absolute fall since 1986 of $34 \%$. There were 4.8 per thousand compared with 7.8 in 1986 a fall of $38 \%$. Whereas in 1986 there were slightly more barium meals than upper gastrointestinal endoscopies, in 1992 there were almost half as many.

\section{Colonoscopies}

Table I shows the number of examinations done both by physicians and surgeons in each of the 20 hospitals and Fig 2 shows the changes in the totals since 1975 . Overall there were $1 \cdot 4$ examinations per thousand of the population,

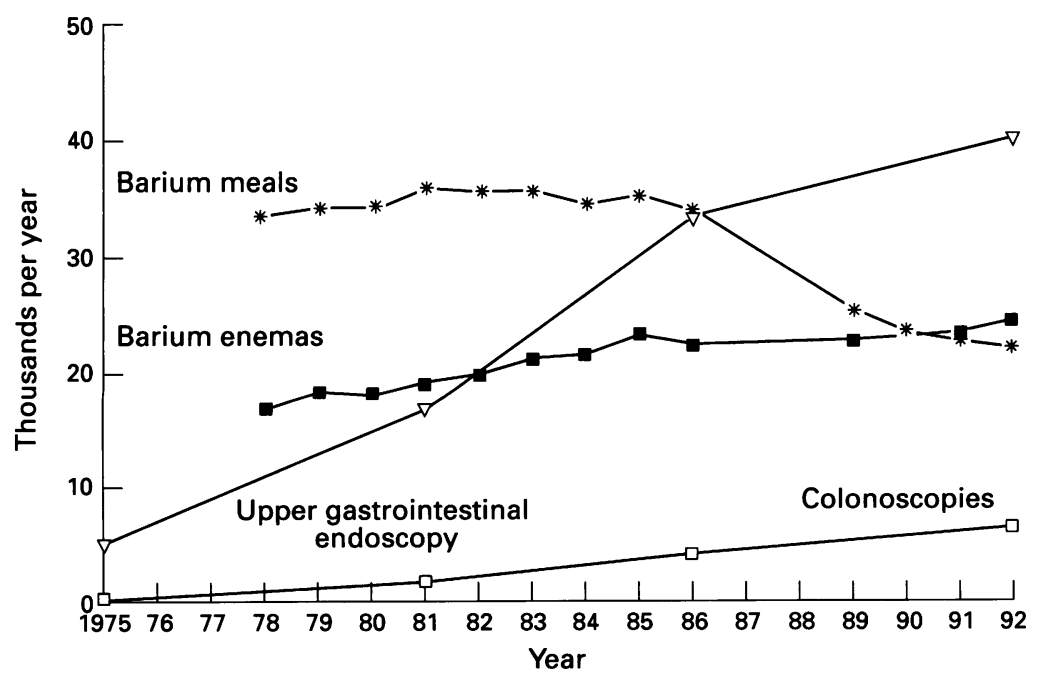

Figure 2: Trent Regional yearly totals since 1975 for gastrointestinal endoscopies and barium radiology. which was an increase of $54 \%$ since 1986 . The absolute increase was $64 \%$. The increase was apparent in all except two of the hospitals. The contribution by surgeons had increased from $54 \%$ to $59 \%$. Table II shows the numbers of barium enema examinations done in each district during 1981, 1986, and 1989-1992 and Fig 2 shows the overall changes. There had been a slight rise in all except three districts, and overall there had been an absolute rise since 1986 of $9 \%$. There were 5.3 per thousand compared with $5 \cdot 1$ in 1986 - a rise of $3 \%$. Barium enemas outnumbered colonoscopies by $3 \cdot 6: 1$ compared with $5 \cdot 4: 1$ in 1986 .

\section{Endoscopy versus barium examinations}

There are now almost the same number of endoscopies (that is, upper gastrointestinal endoscopies plus colonoscopies) as barium examinations -47258 and 47402 respectively. Each amount to one examination per hundred of the population per year.

\section{ERCP}

Table III shows the numbers of ERCPs done in each hospital by both physicians and surgeons. There was an absolute increase since 1986 of $54 \%$ to 2533 examinations. The population based increase was $46 \%$ to 0.54 per thousand. Surgeons did ERCP at five of the hospitals and contributed $27 \%$ of the total examinations. ERCP was not available at seven of the hospitals but it was available in eight of the 11 districts compared with six in 1986 . Forty nine per cent of examinations were therapeutic and, except in three hospitals, this was done only by physicians.

\section{Variceal sclerotherapy}

Table III shows the number of procedures. It was done at 15 of 20 hospitals compared with eight in 1986. Except at one hospital, the Royal Hallamshire, variceal sclerotherapy was done almost only by physicians (there were just two treatments by surgeons at Glenfield Hospital where there was no physician). The Royal Hallamshire Hospital, with a special interest in oesophageal varices, did $63 \%$ of the total and provided the service for the neighbouring districts. There were 0.20 procedures per thousand compared with 0.17 in 1986 . There had been an absolute increase of $21 \%$.

\section{Oesophageal dilatation}

There were 1784 procedures $(0.38$ per thousand) and $486(27 \%)$ were done by surgeons.

\section{Percutaneous endoscopic gastrostomy}

This is a new procedure that has been introduced in 16 of 20 hospitals since the last survey. There was a total of $284(0.06$ per thousand). It was usually done by physicians, including a geriatrician at one hospital, although surgeons contributed, at four of the hospitals, $16 \%$ of the total. There was 
TABLE II Number of barium meals and enemas in the Trent Region in the years 1981-1992

\begin{tabular}{|c|c|c|c|c|c|c|c|c|c|c|c|c|}
\hline \multirow[b]{2}{*}{ District } & \multicolumn{6}{|c|}{ Barium meals } & \multicolumn{6}{|c|}{ Barium enemas } \\
\hline & 1981 & 1986 & 1989 & 1990 & 1991 & 1992 & 1981 & 1986 & 1989 & 1990 & 1991 & 1992 \\
\hline $\begin{array}{l}\text { Barnsley } \\
\text { North Derbys } \\
\text { South Derbys } \\
\text { Doncaster } \\
\text { Leics } \\
\text { North Lincs } \\
\text { South Lincs } \\
\text { North Notts } \\
\text { Nottingham } \\
\text { Rotherham } \\
\text { Sheffield }\end{array}$ & $\begin{array}{l}2154 \\
1746 \\
2419 \\
2162 \\
6149 \\
1658 \\
1964 \\
4655 \\
5575 \\
1523 \\
5894\end{array}$ & $\begin{array}{l}2753 \\
1919 \\
2339 \\
2471 \\
5470 \\
1534 \\
1919 \\
3894 \\
5670 \\
1273 \\
5159\end{array}$ & $\begin{array}{r}1847 \\
1315 \\
2213 \\
2372 \\
3322 \\
958 \\
2222 \\
2991 \\
4307 \\
895 \\
3256\end{array}$ & $\begin{array}{r}1911 \\
1083 \\
1950 \\
2192 \\
2866 \\
974 \\
1962 \\
2962 \\
4181 \\
1018 \\
2766\end{array}$ & $\begin{array}{r}1674 \\
1035 \\
2121 \\
2384 \\
2963 \\
800 \\
1821 \\
2635 \\
4447 \\
867 \\
2608\end{array}$ & $\begin{array}{r}1521 \\
1291 \\
2189 \\
2868 \\
2867 \\
796 \\
1900 \\
1995 \\
4089 \\
828 \\
2266\end{array}$ & $\begin{array}{r}740 \\
820 \\
1356 \\
1248 \\
4025 \\
983 \\
1075 \\
2116 \\
3012 \\
950 \\
2686\end{array}$ & $\begin{array}{r}726 \\
1298 \\
1629 \\
1410 \\
4542 \\
1102 \\
1553 \\
2041 \\
3788 \\
1087 \\
2415\end{array}$ & $\begin{array}{r}926 \\
1349 \\
1709 \\
1524 \\
4384 \\
1246 \\
1919 \\
2333 \\
3895 \\
1059 \\
2758\end{array}$ & $\begin{array}{r}835 \\
1609 \\
1831 \\
1547 \\
4262 \\
1307 \\
1934 \\
2288 \\
4087 \\
1107 \\
2666\end{array}$ & $\begin{array}{r}720 \\
1592 \\
2164 \\
1638 \\
4436 \\
1152 \\
1871 \\
2347 \\
3981 \\
1106 \\
2815\end{array}$ & $\begin{array}{r}657 \\
1851 \\
2262 \\
1860 \\
4515 \\
1370 \\
1735 \\
2359 \\
4205 \\
1075 \\
2903\end{array}$ \\
\hline $\begin{array}{l}\text { Total } \\
\text { Per } 1000 \text { population }\end{array}$ & $\begin{array}{r}35899 \\
8 \cdot 13\end{array}$ & $\begin{array}{r}34401 \\
7 \cdot 79\end{array}$ & $\begin{array}{r}25698 \\
5 \cdot 47\end{array}$ & $\begin{array}{r}23865 \\
5 \cdot 08\end{array}$ & $\begin{array}{r}23355 \\
4.97\end{array}$ & $\begin{array}{r}22610 \\
4 \cdot 81\end{array}$ & $\begin{array}{r}19011 \\
4 \cdot 31\end{array}$ & $\begin{array}{r}22631 \\
5 \cdot 13\end{array}$ & $\begin{array}{r}23102 \\
4.91\end{array}$ & $\begin{array}{r}23473 \\
4.99\end{array}$ & $\begin{array}{r}23822 \\
5 \cdot 07\end{array}$ & $\begin{array}{r}24792 \\
5 \cdot 27\end{array}$ \\
\hline
\end{tabular}

considerable variation among districts, the highest rate being 0.17 per thousand in Nottingham.

\section{Flexible sigmoidoscopy}

It was difficult to get complete figures because this is often done outside the endoscopy unit in the outpatients' clinic. There were at least 3000 procedures shared equally between physicians and surgeons and this varied from 600 at one hospital to none at four hospitals (and just a few at three hospitals). There seemed to be an inverse relation between use of the flexible sigmoidoscope and the colonoscope. Three consultant physicians used flexible sigmoidoscopy routinely in the outpatients' clinic, seldom or never using rigid sigmoidoscopy. Details of bowel preparation was obtained from only 11 of 20 hospitals. Five always used an enema, four often did, and two never used any bowel preparation.

\section{Patient preparation for upper gastrointestinal endoscopy}

In 12 hospitals intravenous sedation was used routinely in nearly all patients. Midazolam was the preferred drug in all except five hospitals where diazepam was used. Lignocaine throat spray was routinely used together with intravenous sedation in 10 of the hospitals. In the eight hospitals not routinely using sedation

TABLE III Number of variceal sclerotherapies and ERCPs in the Trent Region in 1992

\begin{tabular}{|c|c|c|c|c|c|c|c|}
\hline \multirow[b]{2}{*}{ District } & \multirow[b]{2}{*}{ Hospital } & \multicolumn{3}{|c|}{ Variceal sclerotherapy } & \multicolumn{3}{|l|}{$E R C P$} \\
\hline & & Physicians & Surgeons & Total & Physicians & Surgeons & Total \\
\hline Barnsley & Barnsley & 0 & 0 & 0 & 0 & 0 & 0 \\
\hline North Derbys & Chesterfield & 0 & 0 & 0 & 142 & 0 & 142 \\
\hline \multirow[t]{2}{*}{ South Derbys } & Royal & 24 & 0 & 24 & 2 & 0 & 2 \\
\hline & City & 70 & 0 & 70 & 146 & 163 & 309 \\
\hline Doncaster & Doncaster & 11 & 0 & 11 & 142 & 0 & 142 \\
\hline \multirow{3}{*}{ Leics } & Royal & 70 & 0 & 70 & 300 & 0 & 300 \\
\hline & Glenfield & 0 & 2 & 2 & 0 & 157 & 157 \\
\hline & General & 80 & 0 & 80 & 125 & 125 & 250 \\
\hline \multirow[t]{2}{*}{ North Lincs } & Lincoln & 25 & 0 & 25 & 0 & 0 & 0 \\
\hline & Louth & 2 & 0 & 2 & 128 & 0 & 128 \\
\hline \multirow{2}{*}{ South Lincs } & Boston & 30 & 0 & 30 & 0 & 0 & 0 \\
\hline & Grantham & 11 & 0 & 11 & 0 & 0 & 0 \\
\hline \multirow{3}{*}{ North Notts } & Mansfield & 19 & 0 & 19 & 0 & 0 & 0 \\
\hline & Newark & 0 & 0 & 0 & 0 & 0 & 0 \\
\hline & Worksop & 0 & 0 & 0 & 0 & 0 & 0 \\
\hline \multirow[t]{2}{*}{ Nottingham } & City & 13 & 0 & 13 & 129 & 93 & 222 \\
\hline & University & 6 & 0 & 6 & 250 & 31 & 281 \\
\hline \multirow{3}{*}{$\begin{array}{l}\text { Rotherham } \\
\text { Sheffield }\end{array}$} & Rotherham & 0 & 0 & 0 & 85 & 0 & 85 \\
\hline & N General & 9 & 0 & 9 & 241 & 0 & 241 \\
\hline & R Hallamshire & 327 & 256 & 583 & 152 & 122 & 274 \\
\hline \multicolumn{2}{|c|}{$\begin{array}{l}\text { Total } \\
\text { Per } 1000 \text { population }\end{array}$} & 697 & 258 & $\begin{array}{l}955 \\
0 \cdot 20\end{array}$ & 1842 & 691 & $\begin{array}{l}2533 \\
0.54\end{array}$ \\
\hline
\end{tabular}

lignocaine throat spray was always used in two. In five hospitals endoscopy was occasionally done without throat spray or sedation, and in one hospital this happened frequently. A pulse oximeter was available at all except four hospitals. Four of them used it on all sedated patients and the rest just on those at special risk.

\section{Emergency endoscopy}

Endoscopy was available on each weekday in 14 hospitals and at night in 10 hospitals. A weekend service was available in only nine. Bleeding ulcers had been treated with injection, laser or heater probe in 143 patients at 13 of the hospitals.

\section{Site of endoscopy}

Endoscopy was done in a separate gastrointestinal endoscopy unit in four hospitals, in a separate unit shared with bronchoscopy in nine, in a shared day care unit in five, and in a central treatment room in one. Surgeons did their routine endoscopies in the same place as the physicians in all except two hospitals where they did them in the operating theatre.

\section{Open access endoscopy}

Four hospitals offered uncensored open access for general practitioners and a further 10 offered a censored service. All hospitals would arrange endoscopy on the basis of information in a doctor's letter without a previous outpatient appointment. This happened occasionally in eight and often in 12. All hospitals except one had uncensored access for other consultants.

\section{Complications}

There were 19 oesophageal perforations - 10 during dilatation and nine during diagnostic endoscopy. Only one of these caused death. There was a further death from a respiratory arrest during ordinary upper gastrointestinal endoscopy. Four died after ERCP - one after stenting a malignant stricture, two from a perforation of the oesophagus (one of which had previously been treated with radiotherapy), and one, who had carcinoma of the pancreatic head, from a perforated duodenal ulcer. There were two sigmoid perforations at colonoscopy 
and both recovered after surgery. The oesophageal perforation rate for routine upper gastrointestinal endoscopy was one in every 4500 endoscopies. The perforation rate at dilatation was one in every 180 procedures. The mortality for routine diagnostic upper gastrointestinal endoscopy was one in every 20000 examinations, and for ERCP was one in every 630 procedures.

\section{Medical staffing}

Although there had been three new consultant gastroenterologist posts (Chesterfield, Leicester General, and Sheffield Northern General) posts were lost at Leicester Royal and Nottingham University. The total number of consultant gastroenterologists had therefore only increased from 25 to 26 since 1986 . Eleven hospitals had either one or two general practitioner clinical assistants in endoscopy, and six hospitals had unmet requests for one. One hospital had a staff grade doctor in gastroenterology.

\section{Deficiencies in equipment and nurse staffing}

All except four hospitals had video systems for endoscopy but seven hospitals had no videoscope. Ten hospitals had outstanding requests for additional endoscopes that could not be financed by the hospital. Two hospitals had poor recovery facilities. At four hospitals there was insufficient space in the endoscopy unit and three hospitals felt the need for a purpose built unit. Automatic endoscope washing machines were needed for at least three hospitals. Seven hospitals had insufficient nurses/endoscopy assistants. Five hospitals had only two nurses/endoscopy assistants per session. Two units had five and the mean was 3.1. Thirteen hospitals considered that the service was restricted by underfunding of nurse time. Ten of the hospitals had a sister managing the endoscopy unit but some of the smaller hospitals relied on part time nurses just assisting at the endoscopy sessions rather than managing the unit, which was left to the consultant.

\section{Discussion}

This survey has shown that the demand for gastrointestinal endoscopy continues to increase very significantly and it is not clear when this will plateau. This may depend upon gastroenterologists' perception of their role about which there has been some concern. ${ }^{34}$ Many now perceive gastroenterologists as endoscopy technicians and there is increasing pressure for them to behave in that way. Certainly, general practitioners increasingly want a description of the inside of their patients' oesophagus, stomach, and duodenum rather than an opinion on diagnosis and advice on treatment, and 14 hospitals in Trent offered them formal open access. In difficult circumstances with too few consultants and too many outpatients it is usually appropriate to satisfy the general practitioner's desire by providing open access, although it inevitably leads to more unnecessary endoscopies. Hospital managers, who see endoscopy as an important source of revenue, will probably encourage this approach. This has been the traditional approach in radiology but seems inappropriate for gastroenterologists, 'whose education and training should have been that of a cognitive physician who is privileged to provide a helpful diagnostic technique' in addition. ${ }^{4}$ As in all things there needs to be a balance and it behoves gastroenterologists to be circumspect both with regard to how they are being used and their motives. When endoscoping a patient they should be clear whether the procedure is primarily for the benefit of that patient, or part of a strategy to benefit their patients in general, or to raise money for the department or hospital, or to keep on good terms with their GP colleagues, or an easy way out of making a proper clinical assessment, etc. Of course there may be other appropriate reasons for the increasing numbers of endoscopies, such as obtaining gastric antral biopsy specimens for Helicobacter pylori culture and sensitivities, which have affected practice since the last survey.

The number of upper gastrointestinal endoscopies is now almost double that of barium meals and there are now as many gastrointestinal endoscopies (both upper gastrointestinal endoscopies and colonoscopies) as barium examinations. The proportion of complex endoscopic examinations had also increased. Variceal sclerotherapy is now done in 15 and ERCP in 13 of 20 hospitals resulting in an increase of $21 \%$ and $46 \%$ procedures respectively. Half of ERCPs are now therapeutic. Percutaneous endoscopic gastrostomy has become an accepted and preferred means of enteral feeding in those with swallowing difficulties who would otherwise require prolonged nasogastric tube feeding. As the benefits become more appreciated there will probably be a big increase in this procedure. Surgeons continue to contribute significantly to the endoscopy workload, particularly colonoscopies. Although in some regions radiologists contribute to endoscopy, this was not the case in Trent.

One of the values of this survey is that it is population based and complete. The number of procedures should be helpful for strategic planning. There are now 10 gastrointestinal endoscopic procedures for every 1000 of the population per year -8.6 upper gastrointestinal endoscopies and 1.4 colonoscopies. For ERCP there are 0.54 procedures per thousand per year.

Despite this large increase in numbers and complexity of procedures the total number of consultant gastroenterologists had increased only by one - to 26 . Thus there was one consultant for every 180000 of the population compared with one for every 100000 recommended by the British Society of Gastroenterology. ${ }^{5}$ In most cases this increasingly large endoscopy workload is in addition to outpatient consultations and the acute general medical workload, which often exceeds that of physicians in other specialties. ${ }^{6}$

Endoscopy facilities or staffing, or both were unsatisfactory in most hospitals. Without 
considerably increased funding the situation will probably worsen as the Control of Substances Hazardous to Health (COSHH) regulations of the Health and Safety Executive are complied with regarding endoscope disinfection, and as the risks of poor patient supervision before, during, and after endoscopy are appreciated. A minimum of three nurses/ endoscopy assistants per endoscopy room is recommended ${ }^{5}$ and yet at five hospitals there were only two. Pulse oximetry was not available at four hospitals.

One of the most serious deficiencies in the provision of endoscopy services was the nonavailability of emergency endoscopy for major upper gastrointestinal haemorrhage. Although this may be partly related to the availability of experienced endoscopists, financial provision for out of hours nursing is the usual obstacle.

There was considerable variation from hospital to hospital both with regard to number of procedures and techniques. It may not be appropriate to have ERCP at each hospital but it is important that all suitable patients have access to this. It was available in all except three districts and there was no evidence of difficulty referring to a neighbouring district. Knowing the dangers of endoscopy in sedated patients it was perhaps surprising that in only eight of the hospitals was endoscopy routinely done without sedation. Of course, talking nonsedated patients through the procedure may take a little longer and they remember any discomfort, the recounting of which can be upsetting to the endoscopist and other patients.

Despite all the deficiencies it is reassuring that reported serious complications were few - one oesophageal perforation for every 4500 diagnostic upper gastrointestinal endoscopies. At the same time there is no place for complacency and it is important to realise that endoscopy is potentially dangerous and may cause death - at least one in every 20000 diagnostic examinations. Furthermore, these reported complications are probably underestimates as they are not always appreciated at the time of endoscopy and therefore may not be included in the endoscopy records. It is thus incumbent upon gastroenterologists to ensure that as far as possible unnecessary endoscopies are not done. As expected, complications and death were more frequent for therapeutic procedures.

1 Holdsworth CD, Atkinson M. Gastroenterology services: a regional review. $B M F$ 1984; 288: $1245-7$.

2 Scott BB, Atkinson M. Gastroenterology services: a regiona review of changes over a five year period $(1981-86)$. Gu 1989; 30: 695-700.

3 DiSario JA, Waring JP, Sanowski RA, Wadas DD. The gastroenterologist: physician or technician? Gastrointest Endosc 1991; 37: 315-8.

4 Borland JL. Gastroenterologists who also do endoscopy. Gastrointest Endosc 1991; 37: 205-6.

5 Farthing MJG, Williams R, Swan CHJ, Burroughs A Farthing MJG, Williams R, Swan CHJ, Burroughs A,
Heading RC, Dodge JA, et al. Nature and standards of gastrointestinal and liver services in the United Kingdom. gastrointestinal and liver

6 Smith PM, Williams R. A comparison of workloads of physician-gastroenterologists and other consultant physicians. f R Coll Physicians 1992; 26: 167-8. 